\title{
How to support mobility students to gain soft-competences: Knowledge, Skills and Attitudes
}

\author{
Eva M. de la Torre ${ }^{1}$, Fernando Casani², Adriana Pérez Encinas², Jesús Rodríguez \\ Pomeda $^{2}$ \\ ${ }^{1}$ Department of Economics and Public Finance, Universidad Autónoma de Madrid, Spain. \\ ${ }^{2}$ Department of Business Administration, Universidad Autónoma de Madrid, Spain \\ ${ }^{12}$ Research Institute on Higher Education and Science (INAECU), Spain
}

\begin{abstract}
Students participating in mobility experiences have a great learning opportunity, but in many cases they hardly realise about the softcompetences they developed during mobility. In this context, the supporting role of universities is key for students to make the most of their mobility and be able to communicate their learning outcomes. This study analyses the support services that students receive for the development and acknowledgement of mobility soft competencies (related with the three dimensions: knowledge, skills and attitudes or KSAs) in order to define the university strategy in this field. Results show two types of support for outgoing and incoming students: (i) passive initiatives based on delivering relevant information for the mobility period to students; and (ii) active initiatives based on training activities and activities for student integration in the host university/city/culture. No support initiatives on mobility related KSAs for returned students or academic staff have been identified.
\end{abstract}

Keywords: Erasmus; student services; soft competences, knowledge, skills, attitudes.

Erasmus Skills project: Erasmus+ KA203 project number 2018-1-ES01-KA203-050439. More information available in the project website: https://www.erasmusskills.eu/

This project has been funded with support from the European Commission. This communication reflects the views only of the author, and the Commission cannot be held responsible for any use which may be made of the information contained therein. 


\section{Introduction}

Students participating in mobility experiences need to constantly adapt to new circumstances. They change their life-styles, get acquainted with other cultures and some even change habits and attitudes to adapt to the host culture. The mobility experience is a learning opportunity but often students hardly realise about their learning process and are not able to communicate (e.g. to family, friends and most importantly to potential employers) the soft-competences acquired. In this context, the supporting role of universities could go beyond the administrative dimension of student's mobility: they could support students to acknowledge and maximize the learning process and the competences (understood as a combination of knowledge, skills and attitudes - Boyatzis, 1982; Council of Europe, 2018) gained during their adaptation to a new international context. In this way, universities could increase the impact of mobility experiences on students' professional and personal development.

This study analyses the support services that students receive for the development and acknowledgement of mobility related knowledge, skills and attitudes.

\section{Theoretical framework and methodology}

Boyatzis (1982) defines "competence" as the underlying characteristics of the individual causally related to an effective or superior performance in a professional activity; where the individual characteristics are commonly classified in the following three dimensions (Meng et al., 2017): (i) knowledge or the "cognitive" dimension of competence. It refers to all the topics and issues individuals know or need to know to perform a specific task; (ii) skills, the "practical" or applied dimension of competence, which refers to what individuals are able to do or what they need to be able to do to perform a specific task, and (iii) the attitudes (and values) that individuals must espouse in order to perform a specific task effectively. Table 1 shows the sub-dimensions of the mobility-related knowledge, skills and attitudes (KSAs) that we have identified through literature review.

Deardorff (2006) proposes a model for the development of competences in intercultural contexts in which knowledge and skills are individual characteristics that emerge from the mobility experience, but they need an attitudinal background to thrive. Since KSAs are the key ingredients of competences, we put our focus on the learning mobility outcomes understood as KSAs and how its development among mobility students can be supported ${ }^{1}$. In so doing, we perform a preliminary exploration of the institutional initiatives already

\footnotetext{
${ }^{1}$ To our understanding, the KSA approach facilitates students and universities to acknowledge the mobility benefits in detail, without losing the information that a competence approach (more general, complex and abstract) could entail.
} 
implemented for the development and acknowledgement of mobility related KSAs among university students.

Table 1. Dimensions and sub-dimensions of mobility-related competences.

\begin{tabular}{|c|c|c|}
\hline Dimension & Sub-dimension & Source \\
\hline Knowledge & $\begin{array}{l}\text { - Cultural self-awareness: knowledge on one's own culture in the } \\
\text { global context; } \\
\text { - Deep cultural knowledge: knowledge about the other culture in } \\
\text { question; } \\
\text { - Global knowledge: understanding of global issues, processes, } \\
\text { trends, and systems; } \\
\text { - Sociolinguistic awareness; } \\
\text { - Specific higher education knowledge (higher education system, } \\
\text { methods and field-related knowledge). }\end{array}$ & $\begin{array}{l}\text { Deardorff (2006), } \\
\text { Reimers (2009), \& } \\
\text { Gonzáles \& } \\
\text { Wagenaar (2003) }\end{array}$ \\
\hline Skills & $\begin{array}{l}\text { - Ability to acquire, analyse, evaluate information, use cultural } \\
\text { references to think critically and solve practical learning } \\
\text { problems; } \\
\text { - Skills to listen, observe, and relate, as well as communicate and } \\
\text { connect with people from other cultural backgrounds; } \\
\text { - Capacity to use acquired knowledge to extend one's access to } \\
\text { learn the unknown. }\end{array}$ & Piacentini (2017) \\
\hline Attitudes & $\begin{array}{l}\text { - Openness, curiosity and discovery to intercultural opportunities; } \\
\text { - Tolerance and respect to cultural differences and ambiguity. }\end{array}$ & $\begin{array}{l}\text { Hunter (2004), } \\
\text { Deardorff (2006) }\end{array}$ \\
\hline
\end{tabular}

The collection of initiatives was carried out through an online survey. This survey was designed to collect institutional information - name, type of institution and country - and descriptive information on the initiatives, activities or services - name of the initiative, description, related KSAs duration, target audience, assessment and implementation of the initiative, dissemination, etc.

The survey was sent to 749 addresses from European and non-European higher education institutions, companies, foundations and NGOs. The survey received 32 valid answers, being the size of the sample the main limitation of our study - we perform a preliminary descriptive study to provide university practitioners with useful tips for reflecting about the support they provide to students and staff on mobility related KSAs, but we cannot reach extrapolable conclusions, identify general trends or recognise patterns by type of institution or country.

\section{Results}

The analysed initiatives came mostly from universities (26) but also from NGOs (2), community colleges (1), institutes (1), companies (1), and foundations (1). Answers came 
from institutions from 14 different countries, mostly from Europe: Belgium (8), Finland (1), France (2), Germany (2), Greece (4), Italy (4), Poland (1), Portugal (3), Romania, (1), Spain (1), Sweden (2) and The Netherlands (1); but also from the United States of America (1) and Canada (1).

The 32 initiatives collected can be classified into initiatives aimed at supporting students before mobility (53.12\%) and during mobility (46.88\%). We did not identify any initiative supporting students after mobility. As for initiatives assisting (academic or administrative) staff in supporting students, we only found some informative meetings regarding application processes and paper work, but not on KSAs development and student integration processes.

\subsection{Initiatives aimed at supporting students before mobility}

The initiatives supporting students before they participate in mobility experiences have two distinct purposes: (i) encouraging students to participate in international mobility programmes; and (ii) training students in those mobility related KSAs.

There are two types of initiatives that seek to encourage students to participate in international mobility programmes. First, seminars on the international job market (one initiative) in which experts from European companies are invited to share their view on the international industrial context. These seminars are aimed to all students, whether they will participate or not in a mobility programme. And second, international weeks/days to promote mobility (three initiatives) celebrated once a year (usually during the fall term) through workshops and meetings with partners (foreign universities) to inform students about mobility options.

As for those initiatives that offer training in mobility related KSAs, they may be classified as follows: (i) pre-mobility language courses for outgoing Erasmus students (one initiative): in most cases they focus on academic language, but also on general communication skills. (ii) Informative meetings prior to mobility (four initiatives): formal or informal meetings in which outgoing students receive basic information on their arrival to the host country/university (some initiatives include contents related to intercultural competences). They seek to offer information and clarify doubts before mobility. All initiatives facilitate experience exchange and advice between outgoing and returning (or incoming) students. And (iii) workshops/courses/tools on mobility-related KSAs (eight initiatives): face-to-face or online courses for outgoing Erasmus students - some also address other students (e.g. introductory courses to fist year students). Most trainings apply an overall perspective, covering a wide range of KSAs necessary during mobility, e.g. travel safety and health issues, intercultural awareness and cross cultural communication, culture shock, information about the target culture, student learning possibilities, etc. However, some 
initiatives include/are focused on intercultural competences or international employability and job-seeking.

\subsection{Initiatives aimed at supporting students during mobility}

The initiatives supporting students during mobility have the following objectives: (i) the integration of the incoming students in the host city, university and/or culture and (ii) the support of KSAs development. As for those initiatives favouring the integration of the incoming students, we have identified three types. First, welcome meetings to deliver practical information to students (three initiatives) about the university and establish social relationships (e.g. university tour or presentations on administrative processes and services for students). Second, accompaniment initiatives (five initiatives) for incoming students upon their arrival or along their mobility experience in order to facilitate their integration in the city/university/culture. E.g. on-line psychological support, buddy programmes (native students support and advice incoming students), academic guidance by tutors, social and cultural activities and workshops (photography, folk dancing, city tours, etc.). And third, initiatives aiming at achieving active engagement of mobility students with the university context (two initiatives). They include: (i) invitations to international students to deliver presentations on their home countries to school children and (ii) on-campus job/volunteering opportunities were students are encouraged to reflect on their learning process.

The initiatives supporting KSAs development are the following: (i) language courses for incoming students on different languages, including the native language of the host country (two initiatives): these courses are offered in wider programmes together with other courses on non-linguistic KSAs such us conflict resolution or host culture. And (ii), KSA measurement and development (three initiatives): (i) a conceptual framework on international competences gained in volunteering activities during mobility; (ii) a survey on the skills developed by students volunteering on international contexts; and (iii) a digital learning toolkit for personal skills development together with training in communicating the experiences, insights and personal developments achieved during mobility.

\subsection{Mobility related KSAs supported through the initiatives collected}

If we analyse the type of KSAs supported by the 32 initiatives identified, we find that, in our sample, the types of knowledge most addressed before the mobility experience are cultural knowledge (82.4\%) and self-awareness (76.5\%), whilst during the mobility experience the most supported are sociolinguistic awareness $(80 \%)$, followed by cultural knowledge and self-awareness again (both with 73.3\%).

However, there are differences between the other types of knowledge to be acquired. One of them is the importance of cultural knowledge before the mobility experience $(31.43 \%)$ 
and how its interest decreases during the development of the experience $(7.7 \%)$. On the contrary, regarding technical knowledge and knowledge on the educational context, they seem to be types of knowledge expected to be acquired mostly during the mobility experience and not beforehand in our sample (5.71\% and $8.57 \%$ before mobility and $15.4 \%$ in both cases during mobility) - see Figure 1.

As for the skills, there are some differences between the initiatives supporting outgoing or incoming students. Most initiatives address adaptability and communication skills, especially those aimed at helping outgoing students (76.5\%). Other skills most addressed are language skills followed by problem solving or team work. The main concern seems to be the students' adaptation to their host country. Additionally, it is worthy to highlight that very few initiatives support the development of creative thinking and analytical or negotiation skills. This may entail that these skills are usually addressed in our sample in university courses but not through institutional initiatives tailored to incoming students (Figure 2).

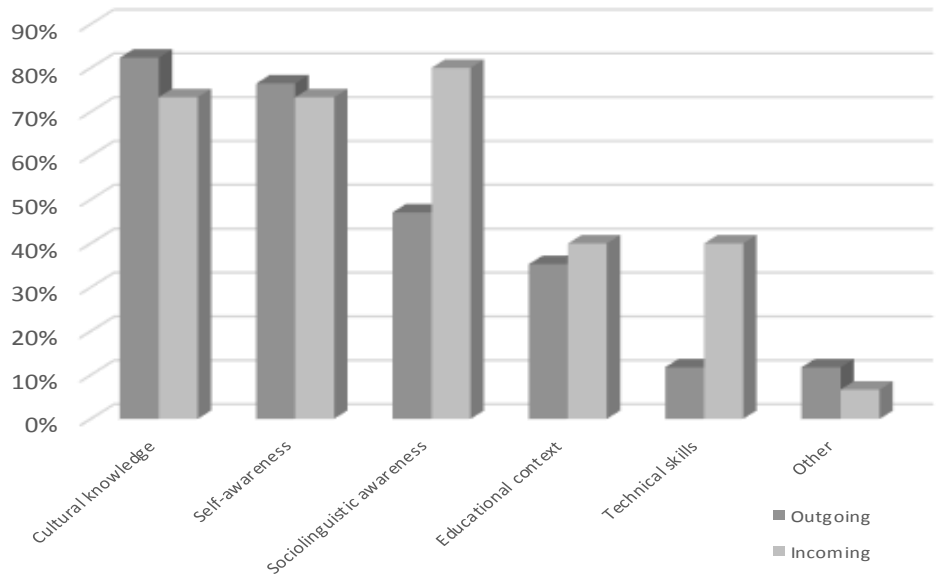

Figure 1. Types of knowledge addressed by the initiatives 


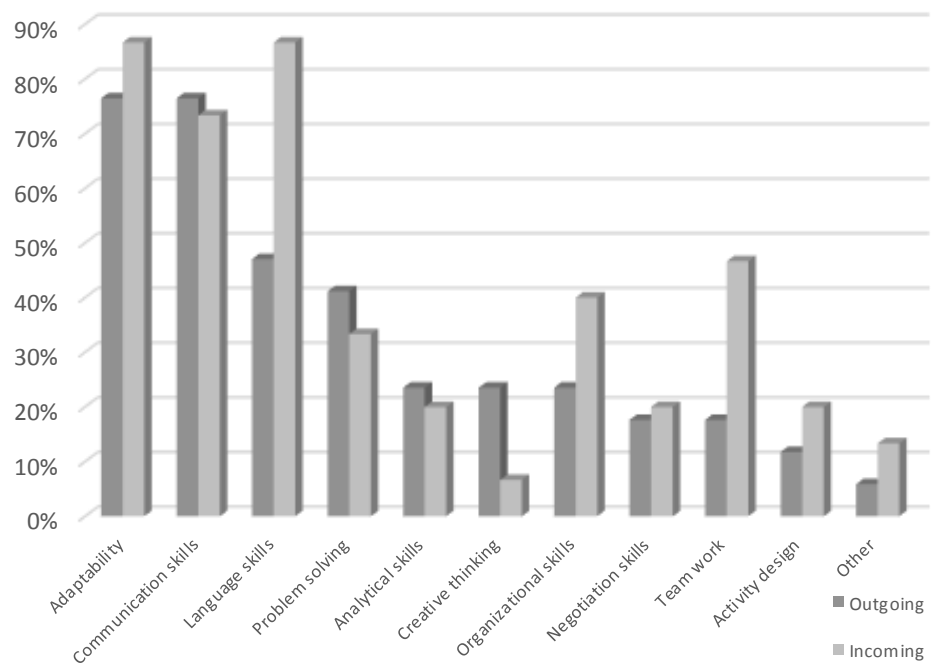

Figure 2. Types of skills addressed by the initiatives

The main attitudes addressed by those initiatives supporting outgoing and incoming students are open mindedness $(88.2 \%$ and $60 \%$ respectively) and transcultural understanding ( $82.5 \%$ and $73.3 \%$ ), but also confidence in the case of incoming students. Both types of initiatives aim mostly at improving empathic attitudes and mental appraisals that support tolerance and understanding towards foreign cultures

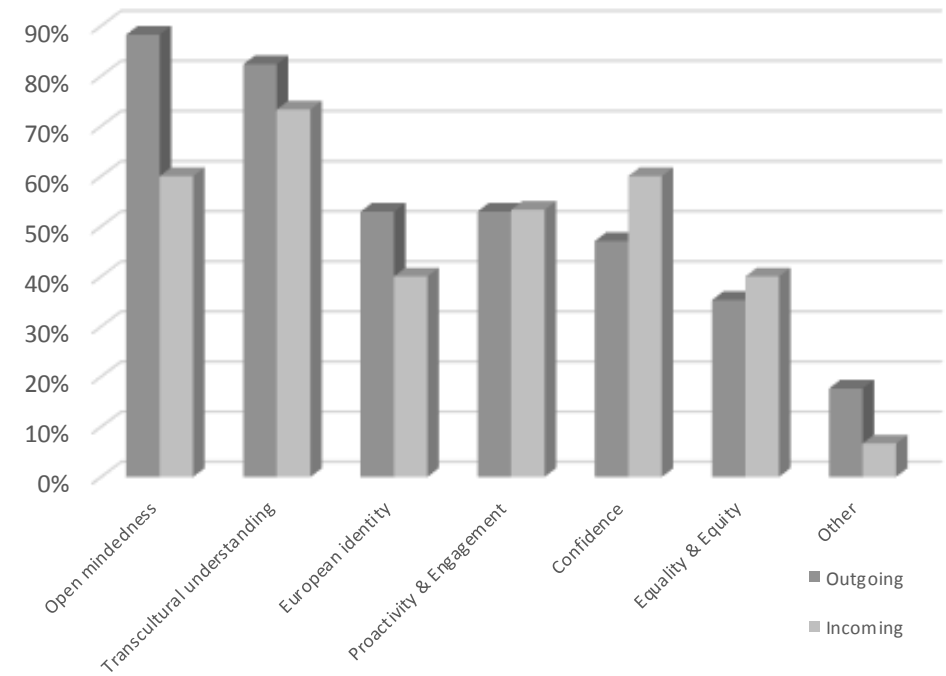

Figure 3. Types of attitudes addressed by the initiatives 


\section{Conclusions}

We have analysed 32 institutional initiatives that provide support to mobility students in their development of KSAs. In future research we will focus on increasing our size sample to reinforce the robustness and extrapolability of our results.

Our sample shows two ways for supporting (outgoing and incoming) students' KSA development: (i) passive initiatives based on delivering relevant information for the mobility period to students; and (ii) active initiatives based on training activities and activities for student integration in the host university/city/culture.

So far, we have not identified any institutional initiative supporting returning students. The only initiatives that involve returned students are those in which they can share their experience with outgoing or incoming students; however, these initiatives do not aim at addressing their specific needs. This gap is aligned with the results of ESNsurvey (Josek et al., 2016), in which Erasmus students reported the lack of support services after mobility, even though coming back to their home country is often a difficult time for mobility students.

We have neither found initiatives aiming at assisting (academic and administrative) staff in supporting students to gain mobility-related KSAs. Indeed, the only initiatives reported that involve university staff consist in providing administrative information on mobility programmes.

Regarding the assessment of the initiatives implemented, the respondent institutions either do not gather any feedback from students or base the initiatives' evaluation on satisfaction questionnaires that do aim to collect information on KSAs development. Gathering KSAs feedback may help in making more explicit this objective, revising initiatives to render them more effective in this sense and reinforcing the students' understanding on the goals of the Erasmus experience.

Also, there are some KSAs that only a few of the identified initiatives support. For example, technical skills and creative thinking are addressed by very few initiatives, probably because in the institutions of our sample they are usually addressed in university courses but not through institutional initiatives tailored to mobility students. Additionally, surprisingly enough, few initiatives support the development of students' European identity or key European values such as equality and equity.

Summarising, we have identified interesting initiatives encouraging the participation in mobility programmes, facilitating incoming students' integration and supporting the development of mobility-related KSAs. Some of these initiatives are very interesting and could be easily extended to most universities. However, universities should define their strategy in this field, making explicit the characteristics of the mobility experience that they 
want to offer and its expected learning outcomes (including KSAs). In this way, they could design a set of activities (and assessment and monitoring tools) that exploits their complementarities and work in a coordinated way as an effective plan to reach the university goals.

\section{References}

Boyatzis, R. E. (1982). The Competent Manager: a Model for Effective Performance. New York: John Wliley and Sons.

Council of Europe (2018). Youth work competence. Retrieved January 2020, from: https://www.coe.int/en/web/youth-portfolio/youth-work-competence

Deardorff, D. K. (2006). Identification and assessment of intercultural competence as a student outcome of internationalization. Journal of studies in international education, 10(3), 241-266. doi: 10.1177\%2F1028315306287002

Gonzáles, J. \& Wagenaar, R. (2003). Tuning Educational Structures in Europe. Bilbao: Universidad de Deusto Retrieved January 2020, from: http://tuningacademy.org/wpcontent/uploads/2014/02/TuningEUI_Final-Report_EN.pdf

Hunter, W. (2004). Knowledge, skills, attitudes, and experiences necessary to become globally competent. UMI Dissertation Services, Lehigh University.

Josek, M. et al. (2016). The international-friendliness of universities: Research report of the ESNsurvey 2016. Erasmus Student Network AISBL. ESN.org. Retrieved January 2020, from https://esn.org/ESNsurvey

Meng, Q., Zhu, C., \& Cao, C. (2017). An exploratory study of Chinese university undergraduates' global competence: effects of internationalisation at home and motivation. Higher Education Quarterly, 71(2), 159-181. doi: 10.1111/hequ.12119

Piacentini, M. (2017). Developing an International Assessment of Global Competence. Childhood Education, 96(6), 507-510. doi: 10.1080/00094056.2017.1398564

Reimers, F. (2009). Educating for Global Competency. In J. E. Cohen \& M. B. Malin (eds.), International Perspectives on the Goals of Universal Basic and Secondary Education (183-202). New York: Routledge. 